\title{
Verbal retrieval cues prevent renewal and spontaneous recovery of predictive judgments in university students
}

\section{Las señales de recuperación verbal evitan la renovación y la recuperación espontánea de juicios predictivos en estudiantes universitarios}

\author{
Angélica Serena Alvarado García ${ }^{\mathrm{a}}$, Rodolfo Bernal-Gamboa, ${ }^{\mathrm{b},}$, Javier Vila Carranza ${ }^{\mathrm{b}}$ \\ anstituto Politécnico Nacional CICS-UST, México \\ bUniversidad Nacional Autónoma de México, México
}

\begin{abstract}
Long-term effectiveness is one of the major problems of psychotherapy because successfully eliminated unhealthy behaviors may reappear relatively easily under certain contextual changes. In two experiments, we explored the impact of verbal retrieval cues on renewal and spontaneous recovery in humans. During the first phase, all participants learned a relationship between one cue and one outcome (X-O1). The following phase involved a change in the original relationship (X-O2). Finally, participants were presented with cue $\mathrm{X}$ and asked about the relationships with both outcomes. Half of the participants were asked to remember Phase 2, while the other half did not receive any instruction at all. In Experiment 1, testing took place in a different context, while participants in Experiment 2 were tested after two days. The results indicated that remembering Phase 2 eliminated both renewal and spontaneous recovery. Our findings are discussed under the contemporary learning theory. We also mention the probable benefits in therapeutic settings.
\end{abstract}

Keywords: verbal retrieval cues, retroactive interference, renewal, spontaneous recovery, high-school students.

Para citar este artículo:

Alvarado, A. S., Bernal-Gamboa, R., \& Vila, J. (2018). Verbal retrieval cues prevent renewal and spontaneous recovery of predictive judgments in university students. Liberabit, 24(2), 309-319. https://doi.org/10.24265/ liberabit.2018.v24n2.10

\section{Resumen}

Uno de los principales problemas de las psicoterapias es su efectividad a largo plazo porque las conductas poco saludables que se eliminaron exitosamente pueden reaparecer con relativa facilidad bajo ciertos cambios contextuales. En dos experimentos, exploramos el impacto de señales de recuperación verbales en la renovación y en la recuperación espontánea en humanos. En la primera fase, todos los participantes aprendieron una asociación entre una clave y una consecuencia (X-O1). La siguiente fase involucró un cambio en la relación original (X-O2). Finalmente, se les presentó a los participantes la clave $\mathrm{X}$ y se les preguntó acerca de las asociaciones con las dos consecuencias. A la mitad de los participantes se les pidió que recordaran la Fase 2, mientras que la otra mitad no recibió ninguna instrucción. En el Experimento 1, la prueba se condujo en un contexto diferente, mientras que en el Experimento 2 la prueba se realizó dos días después. Los resultados indicaron que recordar la Fase 2 eliminó tanto la renovación como la recuperación espontánea. Nuestros hallazgos se discuten bajo la teoría contemporánea del aprendizaje. Asimismo, se mencionan probables beneficios para escenarios terapéuticos.

Palabras clave: señales verbales de recuperación, interferencia retroactiva, renovación, recuperación espontánea, estudiantes de bachillerato.

Este es un artículo Open Access bajo la licencia Creative Commons Atribución-NoComercial-CompartirIgual 4.0

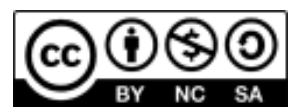




\section{Introduction}

Cognitive behavioral therapy has proven to be an effective treatment to manage unhealthy thoughts, emotions, and behaviors (Craske, Treanor, Conway, Zbozinek, \& Vervliet, 2014). Nevertheless, the major challenge to this kind of therapy is not to reduce the psychological disorder but to prevent its relapse (Vervliet, Craske, \& Hermans, 2013). There are several reports that indicate that patients reexperience their symptoms even after a successful clinical intervention (Craske, Hermans, \& Vervliet, 2018; Pritchard, Hoerger, \& Mace, 2014).

Given that the strategies to eliminate unwanted behaviors in the cognitive behavioral therapy are based on extinction (the omission of the unconditioned stimulus [US] produces a response decrement), some learning theorists have pointed out that a possible insight might come from basic research (Bouton, 2017; Laborda, Polack, Miguez, \& Miller, 2014; Podlesnik \& Kelley, 2015). Evidence from laboratory is provided by different sources of relapse (Bouton, 2017). For example, renewal refers to the effect that, after extinction, if the conditioned stimulus (CS) is tested in a context distinct from the extinction context, a strong conditioned response (CR) is again observed (Bouton \& Bolles, 1979). There are three different designs of renewal: $\mathrm{ABA}, \mathrm{ABC}$ and $\mathrm{AAB}$ (the letters indicate the context where conditioning, extinction and testing take place). Thus, in ABA renewal, conditioning and testing are carried out in the same context (Vila \& Rosas, 2001). For ABC renewal, each phase is conducted in a different context (Nelson, Sanjuan, Vadillo-Ruiz Pérez, \& León, 2011). Finally, in AAB renewal, conditioning and extinction take place in the same context, while testing is experienced in a second context (Rosas \& Callejas-Aguilera, 2006). Another source of relapse that takes place after extinction is spontaneous recovery (Pavlov, 1927). According to Pavlov's pioneer experiment, an extinguished behavior reappears after some time has elapsed in spontaneous recovery (Vila \& Rosas, 2001).
Various researchers have claimed that understanding the mechanisms underlying renewal and spontaneous recovery may be helpful to comprehend post-therapy relapse (Craske et al., 2014; Podlesnik, Kelley, Jimenez-Gomez, \& Bouton, 2017; Vervliet et al., 2013). Nowadays, the most accepted account for these effects is the Retrieval Theory of Forgetting (RTF) elaborated by Mark Bouton (1993). The RTF assumes that all events in the world and the relationships among them are represented as nodes of information within the associative memory. A memory of conditioning is formed after pairing the CS (e.g., a snake) with the US (e.g., a disruptive emotional response). When the organism is exposed to interfering information like in extinction, in which the CS no longer predicts the US (or, in therapy, where the feared object is not followed by any traumatic event), the memory of conditioning is not erased; rather, a new memory is created. This new memory retroactively interferes with the first memory of conditioning producing a significant reduction in the original response (e.g., phobia). However, the RTF proposed that, given that the new memory would be especially sensitive to the context where it was learned, it would not be retrieved outside of the extinction context (therapist's office). So, if the organism leaves the extinction context, the individual would recover the memory of conditioning, and therefore relapse would occur (Ogállar, Ramos-Álvarez, Alcalá, Moreno-Fernández, \& Rosas, 2017; Rosas, CallejasAguilera, Ramos-Álvarez, \& Abad, 2006).

Because the RTF proposes that the key to relapse (recovery of the memory of conditioning) is not returning to the conditioning context but is leaving the extinction context, this theory easily predicts all three forms of renewal (McConnell \& Miller, 2014). Note that, despite the methodological differences between renewal and spontaneous recovery, the RTF considers spontaneous recovery as a special case of AAB renewal in which the time of extinction (T1) and the time of testing (T2) are taken as distinct temporal contexts (Bouton, 2017; Rosas, Todd, \& Bouton, 2013). 
Aside from providing a clear explanation, the RTF provides a fundamental idea to develop behavioral techniques in order to prevent relapse: if relapse occurs due to a failure to retrieve the therapeutic abilities (extinction) outside of the clinical setting, then, using methods that facilitate the remembrance of the therapeutic learning should reduce relapse. Supporting that prediction, reports have found that using retrieval cues from extinction prevents renewal in both humans (Dibbets, Havermans, \& Arntz, 2008; Vansteenwegen et al., 2006) and nonhuman animals (Brooks \& Bouton, 1994; Nieto, Uengoer, \& Bernal-Gamboa, 2017; Willcocks \& McNally, 2014). There is also evidence that parallels the effects on spontaneous recovery with rats (Bernal-Gamboa, Gámez, \& Nieto, 2017; Brooks \& Bouton, 1993).

Although most of the studies used physical retrieval cues, e.g., a pen with humans (Laborda et al., 2016) or lights with rats (Bernal-Gamboa et al., 2017), it has been argued that, given that retrieval objects are not always available, patients could use mental retrieval cues (Craske et al., 2008, 2014). For example, if a patient is confronted with a fear-provoking stimulus, imagining what the clinician would have said could be very helpful to reduce the phobic behavior. This type of strategy has been used only in situations that involve aversive situations such as the fear of spiders (Mystkowsky, Craske, Echiverri, \& Labus, 2006) or fear of public speaking (Culver, Stoyanova, \& Craske, 2011; Laborda et al., 2016). Hence, the main goal of the present experiments was to explore the impact of mental retrieval cues (produced by verbal instructions) on the renewal (Experiment 1) and spontaneous recovery (Experiment 2) of predictive judgments in healthy humans. Given that this strategy is based on a memory model (RTF), extending the results of aversive situations to a neutral situation (predictive learning) in students may strength the generality of the mental retrieval cues and contribute to a better understanding of the underlying mechanisms of verbal reminder signals.

The designs are presented in Table 1. During Phase 1 , participants first learned in a fictitious task that consumption of one drug (cue $\mathrm{X}$ ) produced fever (outcome O1) in a particular hospital (Context A). Then, in Phase 2, instead of using an extinction treatment, we conducted another type of interference learning (patients acquired new knowledge in psychotherapy that retroactively interfered with the unhealthy behavior). So, all participants learned that consumption of $\mathrm{X}$ did not produce $\mathrm{O} 1$ anymore but nausea (O2) in Context A. Finally, participants were asked about the relationship between $\mathrm{X}$ and both outcomes. In Experiment 1, testing was conducted in a different hospital (Context B), whereas in Experiment 2 testing occurred 48 hours after Phase 2. Before testing, only half of the participants were verbally instructed to remember Phase 2 . According to the RTF, the verbal retrieval cues should reduce the response recovery in both experiments.

\section{Method}

\section{Participants}

Forty-four (44) high-school students (24 in Experiment 1 and 20 in Experiment 2) from the National Autonomous University of Mexico (Mexico) participated in this study (31 women, 13 men; $M$ age $=18.25$ years; age range $=15-21$ years). They had no previous experience with the task. All students participated voluntarily and gave their informed consent before beginning the experiment, being free to abandon the task at any point of the process, although none of them did.

\section{Apparatus and stimuli}

The experiment took place in a 4 x $6 \mathrm{~m}$ room. In the front wall of the room, a standard projection screen was placed $(180 \times 185 \mathrm{~cm})$. The task was projected on the screen with a video projector which was connected to a laptop controlled by the experimenter. The procedure was implemented using the SuperLab Pro (Cedrus Corporation) software. The stimulus used as fictitious medicine $\mathrm{X}$ was Batim, whereas the side effects were fever and nausea (counterbalanced). The task was similar to the one used by Alvarado, Jara, Vila, and Rosas (2006). 
Table 1

Experimental Designs

\begin{tabular}{ccccc}
\hline Experiment & Group & Phase 1 & Phase 2 & Test \\
\hline 1 & & & & \\
& AAB_Nc & A: X-O1 & A: X-O2 & B: X \\
2 & AAB_Vc & A: X-O1 & A: X-O2 & B*: X \\
& 48h_Nc & A: X-O1 & A: X-O2 & A: X \\
& 48h_Vc & A: X-O1 & A: X-O2 & A*: X \\
\hline
\end{tabular}

Note: «Context A» and «Context B»: Saint Louis Hospital and Multimedic Hospital, counterbalanced. «X»: stands for a fictional drug: Batim. «O1» and «O2»: fever and nausea, counterbalanced. «*» stands for the verbal retrieval cue. Testing for Experiment 1 took place in Context B, whereas testing for Experiment 2 was conducted 48 hours after the last trial of Phase 2. See text for details.

\section{Procedure}

The study protocol was conducted in strict agreement with the guidelines established by the Ethical Committee of the National Autonomous University of Mexico's Faculty of Psychology. Participants were run in sets of 5 or 6 (all in one group). They entered the room and sat around the table with a space among them of approximately 120 $\mathrm{cm}$. All participants received two types of paper sheets, which had a two-column table. The left column consisted of the trial number (from 1 to 41). The right column was empty, so that participants could write down their response to each trial. The evaluation sheet was a hard copy of the screen in which causal judgments were going to be requested, as described below. All of the instructions were in Spanish.

The following instructions were projected on the screen while the experimenter read them out loud: It has been detected in the city of Guadalajara that some patients presented certain side effects after ingesting a specific medicine. You will see some sets of patient files. Your work will be to determine whether the medicine produces the side effect and write it down on your response sheet; once you write it down, you will observe the side effect experienced by the patient. This information will allow you to learn the relationship between the medicine and the side effects.
Your response will be random at the beginning, but you will soon become an expert. If at any point you detect some changes in the experiment, please continue because they are part of the experiment. Finally, remember that you can take all the time you need.

The screen was configured as follows. The background was white. The name of a hospital (Saint Louis Hospital or Multimedic Hospital) was placed on the top center of the screen. The sentence «This patient ingested Batim; this medicine produced...» appeared immediately below the name of the hospital. Below that sentence, the side effects «fever» and «nausea» were presented in two separate rows. Then, a screen was displayed where, below the name of the hospital, the following sentence was written down: «Please write down the degree to which you think that taking Batim causes each of the following side effects. Use a scale from 0 to 100 , where 0 means that it never causes a side effect, and 100 means that it always causes it.» Below this sentence, on the left part of the screen, both side effects were presented. To the right of each side effect, there was an empty square. At the bottom of the screen, a 0-100 scale was shown with labels on points $0,32,50,68$, and $100 \%$. The sentences «It never caused the side effect,» «It sometimes caused the side effect,» and «It always caused the side effect» appeared below 0 , 50 , and 100 , respectively. Participants had to write 
down their evaluation about the judged relationship between the medicine and each side effect within the empty box that appeared next to each side effect. Participants had enough evaluation sheet hard copies to complete the experiment. Participants were instructed to turn down the sheets once they were filled out, and not to glance at them anymore under any circumstance. In sum, participants had to write down their evaluation on both sheets. For example, on trial 1 they could write down «50» on the right of each side effect (evaluation sheet), and then write down «50/50» on the right column of the response sheet.

\section{Experiment 1}

Participants were randomly assigned to one of the two groups used in the experiment: AAB_Nc (no cue) and AAB_Vc (verbal cue). See the experimental design in the first row of Table 1.

Phase 1. Participants received 20 trials in which Batim (X) was followed by O1 (fever or nausea) in Context A (Saint Louis Hospital or Multimedic Hospital).

Phase 2. All participants received 20 trials in the same Context A as in the previous phase, except that $\mathrm{X}$ was paired with $\mathrm{O} 2$. For example, if Batim was predictive of nausea in Phase 1, then it was predictive of fever in Phase 2.

Test. For participants in Group AAB_Vc, this phase began with the following instruction on the screen: «Before seeing more files, please remember the last information you have learned.» Group AAB_Nc received the next instruction on the screen: «Please continue seeing more files.» After that, all participants received a test trial in extinction. The trial was the same as in Phase 2, but it was conducted in Context B.

\section{Experiment 2}

Participants were randomly assigned to one of the two groups used in the experiment: 48h_Nc (no cue) and 48h_V (verbal cue). See the experimental design in the first row of Table 1. Except as noted, the same procedure as in Experiment 1 was used.

Test. This phase took place after Phase 2. Before testing, participants in Group 48h_Nc received the next instruction on the screen: «Please continue seeing more files.» On the other hand, for participants in Group $48 \mathrm{~h}$ _Vc, the following instruction was projected on the screen: «Before seeing more files, please remember the last information you have learned.» Afterwards, both groups received a test trial in extinction. The trial was the same as in Phase 2 and it was conducted in Context A.

\section{Dependent Variable and Statistical Analysis}

Predictive judgments were requested throughout Phase 1, Phase 2, and Test. The data was analyzed using the analysis of variance (ANOVA). The rejection criterion was set at $\mathrm{p}<.05$, and effect sizes were reported using partial eta-squared $\left(\eta \mathrm{p}^{2}\right)$.

\section{Results and Discussion of Experiment 1}

Figure 1 shows the mean predictive judgments given by both groups for $\mathrm{O} 1$ and $\mathrm{O} 2$ during the 5trial block of Phase 1 (left panel), Phase 2 (middle panel), and Test (right panel). A 2 (Group AAB_Nc vs. AAB_Vc) x 2 (Phase 1 vs. 2 ) x 2 (Outcome O1 vs. O2) ANOVA using data from Phase 1 and Phase 2 confirmed that participants' ratings were different depending on the phase they experienced, given that only the Phase $\mathrm{x}$ Outcome interaction was significant: $F(1,44)=273.97, p=.001, \eta p^{2}=.86$. Subsequent analyses confirmed that, during Phase 1 , participants showed higher ratings for $01, F(1,44)=203.24, p$ $=.01$, while the ratings for $\mathrm{O} 2$ were higher in Phase $2, F(1,44)=72.73, p=.001$, indicating that participants correctly learned the discrimination. 


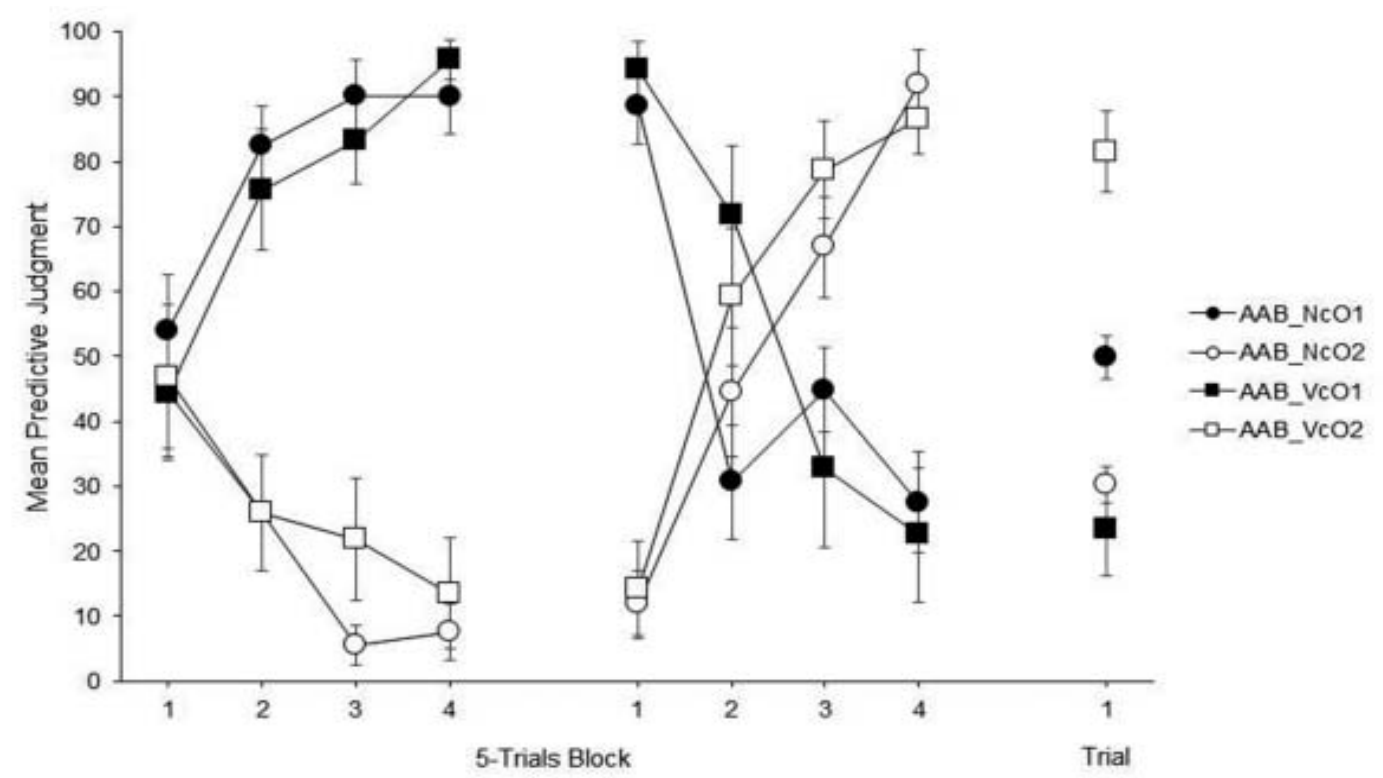

Figure 1. Mean predictive judgments for $O 1$ and $O 2$ from Phase 1 (left panel), Phase 2 (middle panel), and Test (right panel). Error bars denote standard errors of the mean.

The right panel of Figure 1 shows the mean predictive judgments during the Test for $\mathrm{O} 1$ and $\mathrm{O} 2$ in Context B. If a mental retrieval cue is effective to reduce the $A A B$ renewal, then participants that received the verbal instruction to remember Phase 2 should show lower predictive judgments for $\mathrm{O} 1$ than for $\mathrm{O} 2$.

A 2 (Group AAB_Nc vs. AAB_Vc) x 2 (Outcome O1 vs. O2) ANOVA found a significant main effect for Group, $F(1,22)=15.52, p=.001, \eta p^{2}=.41$, and Outcome, $F(1,22)=8.27, p=.008, \eta p^{2}=.27$. The Group $x$ Outcome interaction was significant as well: $F(1,22)=33.80, p=.001, \eta p^{2}=.61$. Exploring this interaction, we found that participants in Group AAB_Nc showed a higher rating for $\mathrm{O} 1$ than for O2, $F(1,22)=4.32, p=.04$, indicating that $\mathrm{AAB}$ renewal of predictive judgments took place. However, the most important result was that ratings for Group AAB_Vc regarding $\mathrm{O} 1$ were lower than those of $\mathrm{O} 2, F(1,22)$ $=37.75, p=.001$. Moreover, ratings for Group AAB_Vc regarding $\mathrm{O} 1$ were lower than ratings for Group AAB_Nc regarding $\mathrm{O} 1, F(1,22)=11,31, p$
$=.002$, showing that a mental retrieval cue eliminated the $\mathrm{AAB}$ renewal in a predictive learning task.

\section{Results and Discussion of Experiment 2}

Figure 2 shows the mean predictive judgments given by Groups 48h_Nc and 48h_Vc for both outcomes throughout Phase 1(left panel), Phase 2 (middle panel) and Test (right panel). A 2 (Groups, 48h_Nc vs. 48h_Vc) x 2 (Phase, 1 vs. 2) x 2 (Outcomes, O1 vs. O2) ANOVA using data from Phase 1 and Phase 2 confirmed that participants' performance fulfilled the contingencies received on each phase, because only the Phase $\mathrm{x}$ Outcome interaction was significant: $F(1,36)=522.36, p=$ $.001, \eta p^{2}=.94$. No other main effect or interaction involving the factors were significant: $F(1,36)=1.98$, $p=.16$. Planned comparison found that participants rated higher $\mathrm{O} 1$ than $\mathrm{O} 2$ during Phase $1, F(1,36)=$ $188.80, p=.001$, whereas the opposite was true during Phase 2, $F(1,36)=346.96, p=.01$. These results confirmed that both groups learned the contingencies in a correct manner. 


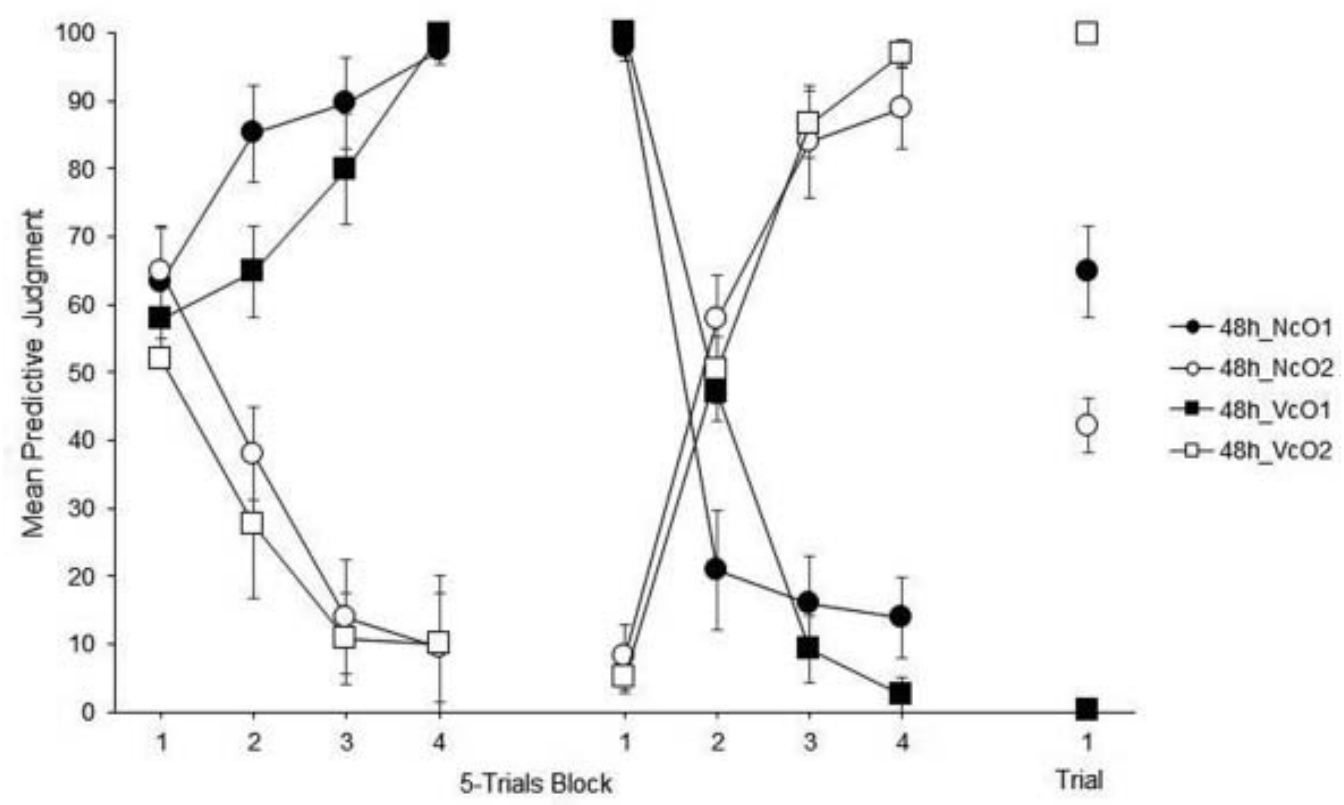

Figure 2. Mean predictive judgments for $\mathrm{O} 1$ and $\mathrm{O} 2$ from Phase 1(left panel), Phase 2 (middle panel), and Test (right panel). Error bars denote standard errors of the mean.

Figure 2 depicts the mean predictive judgments for $\mathrm{O} 1$ and $\mathrm{O} 2$ during the Test that was conducted 48 hours after the last trial of Phase 2. According to the RTF, spontaneous recovery is a special case of AAB renewal. Thus, because a mental retrieval cue prevents $\mathrm{AAB}$ renewal, a similar result is expected in the spontaneous recovery effect of predictive judgments with humans.

A 2 (Group 48h_Nc vs. 48h_Vc) x 2 (Outcome $\mathrm{O} 1$ vs. O2) ANOVA conducted with data from the Test found that the main effect of Group was not significant, $F(1,18)=1.83, p=.19$. However, the main effect of Outcome, $F(1,18)=61.71, p=.001$, $\eta \mathrm{p}^{2}=.77$, and the Group $\mathrm{x}$ Outcome interaction were significant, $F(1,18)=155.12, p=.001, \eta p^{2}=.89$. Subsequent analyses found a spontaneous recovery effect, because Group 48h_Nc showed higher ratings for O1 than for O2: $F(1,18)=10.57, p=.004$. The most important data of the present experiment was provided by participants in Group 48h_Vc. These participants reported lower ratings for $\mathrm{O} 1$ than for $\mathrm{O} 2$ :
$F(1,18)=206.26, p=.001$. In addition, the analyses indicated that ratings for Group 48h_Vc regarding O1 were also lower than ratings for Group 48h_Nc regarding $\mathrm{O} 1, F(1,18)=93.38, p=.001$, which shows that using a mental retrieval cue also thwarted a spontaneous recovery of predictive judgments.

\section{General Discussion}

The goal of the present experimental series was to evaluate whether mental retrieval cues have any effect on $A A B$ renewal and spontaneous recovery of predictive judgments with human participants. Using a within-subject design, we found both renewal and spontaneous recovery in a predictive learning task (higher ratings for $\mathrm{O} 1$ than for O2). However, our most important discovery, though limited to human predictive learning and reported for the first time to the best of our knowledge, is that asking participants to retrieve the information learned in Phase 2 eliminated both sources of relapse (lower ratings for O1 than for O2). 
The relevance of using verbal cues on human performance has been noted elsewhere (Romero, Vila, \& Rosas, 2005). For example, showed in a matchingto-sample task with humans that verbal instructions could be used as context (Romero et al., 2005). They found that changing the instructional context after reversal training led to $\mathrm{ABA}$ and $\mathrm{AAB}$ renewal. In addition, Mystkowski, Craske, Echiverri, and Labus, (2006) reported the first study that evaluated the impact of verbal cues on reducing information retrieval. Those authors exposed arachnophobic participants with one session of exposure-based treatment in a particular context (e.g., a laboratory room). Then, one week later, participants' fear levels were registered in the same context or in a new context (e.g., a small patio). Before testing, half of the participants were asked to remember all the information learned and the context where it was learned, while the other half were asked to remember the things they did on a regular morning. On the test phase, all participants encountered the phobic stimulus (i.e., a tarantula). The most important result was that only those participants who received the verbal instruction reported less levels of fear when the testing took place in the new context, indicating a reduction of a special case of $\mathrm{ABC}$ renewal. Thus, our findings from Experiment 1 are consistent with the results presented by Mystkowski et al. (2006) and extended to an $\mathrm{AAB}$ renewal involving predictive learning.

On the other hand, Mystkowski et al. (2006) did not find any reduction in self-reported fear in participants that received the verbal instructions in the same context one week later (e.g., spontaneous recovery). Our results from Experiment 2 are inconsistent with those of Mystkowski et al. (2006), because our findings showed the effectiveness of a verbal retrieval cue to prevent spontaneous recovery in a predictive learning task. A possible explanation might be related to the length of the retention interval. In our study, testing was conducted two days (48 hours) after Phase 2, while Mystkowski et al. (2006) carried out the test seven days after the Treatment Phase, suggesting a limitation for the mental retrieval cues (i.e., their effectiveness may be greater on shorter periods of time). In addition, our data from Experiment 2 is at odds with reports that showed a lack of effect of verbal retrieval cues on reducing fear of public speaking (Culver et al., 2011; Laborda et al., 2016). Although this inconsistency could suggest that the critical difference between each paradigm may depend on the emotional content involved (i.e., fear vs. fictional events), note that both studies summates physical and temporal contexts, thereby producing a larger recovery effect than either of these manipulations alone (Laborda et al., 2014). Thus, more research is needed for a better understanding of the underlying mechanisms of each paradigm.

Nevertheless, the above-mentioned studies (Culver et al., 2011; Laborda et al., 2016; Mystkowski et al., 2006) and our experimental series concur with the RTF stance that proposes that relapsing involves contextual changes. Therefore, the retrieval cues provide a bridge between the interfering context (therapy) and the renewal context (relapse).

Although the verbal retrieval cues have received little attention, the bridge strategy (Bouton, 2017) has been successfully proved with physical retrieval cues both in humans (Laborda et al., 2016) and rats (Brooks \& Bouton, 1994) in a variety of conditioning preparations (Bernal-Gamboa, et al., 2017; Dibbets et al., 2008). Thus, the overall pattern of results favors the RTF above other explanations for sources of relapse.

Given that participants received the verbal instruction to remember the last information learned before testing, an alternative account for our data could be the fact that the instructions might have distracted the participants. However, the direction of the ratings is hardly explained by this account (higher ratings for O2). If participants had indeed been distracted, similar levels of ratings would be expected for both outcomes.

In the present paper, we suggested that the verbal retrieval cues made participants recall the learning 
from Phase 2. However, given that participants neither spoke out loud nor wrote down their memories, we are unsure what participants remembered. Because new therapeutic strategies could be based on the verbal-retrieval-cue procedure, it is important to conduct more studies that allow researchers to know the content of mental rehearsal, in order to fully understand what details from the memory are preventing the relapse. In addition, future research should investigate the mechanisms and the limitations of the verbal retrieval cues (Cerutti, 1989).

\section{Conflicts of interest}

The authors declare that there is no conflict of interests.

\section{Ethical Responsibility}

The present research was conducted with voluntary high-school students. Every student signed an informed consent form. The study protocol was conducted in strict agreement with the guidelines established by the Ethical Committee of the National Autonomous University of Mexico's Faculty of Psychology. Participants' age and gender were the only data appearing in the manuscript, which was not linked to a name or identity.

\section{Acknowledgments}

This manuscript was supported by UNAM/ DGAPA-PAPIIT IN301315 and IA302818.

\section{References}

Alvarado, A., Jara, E., Vila, J., \& Rosas, J. M. (2006). Time and order effects on causal learning. Learning and Motivation, 37, 324-345. http://dx.doi.org/10.1016/ j.lmot.2005.11.001

Bernal-Gamboa, R., Gámez, A. M., \& Nieto, J. (2017). Reducing spontaneous recovery and reinstatement of operant performance through extinction-cues. Behavioural Processes, 135, 1-7. http://dx.doi.org/ 10.1016/j.beproc.2016.11.010

Bouton, M.E. (1993). Context, time, and memory retrieval in the interference paradigms of pavlovian learning. Psychological Bulletin, 114, 80-99. http:// dx.doi.org/10.1037/0033-2909.114.1.80

Bouton, M. E. (2017) Extinction: Behavioral mechanisms and their implications. In R. Menzel (ed.), Learning Theory and Behavior, Vol. 1 of Learning and Memory: A Comprehensive Reference (2nd edition, Byrne, J.H. (ed.). pp. 61-83). Oxford: Academic Press.

Bouton, M. E., \& Bolles, R. C. (1979). Contextual control of the extinction of conditioned fear. Learning and Motivation, 10, 445-466. http:// dx.doi.org/10.1016/0023-9690(79)90057-2

Brooks, D. C., \& Bouton, M. E. (1993). A retrieval cue for extinction attenuates spontaneous recovery. Journal of Experimental Psychology: Animal Behavior Processes, 19, 77-89. http://dx.doi.org/ 10.1037/0097-7403.19.1.77

Brooks, D. C., \& Bouton, M. E. (1994). A retrieval cue for extinction attenuates response recovery (renewal) caused by a return to the conditioning context. Journal of Experimental Psychology: Animal Behavior Processes, 20, 366-379. http://dx.doi.org/ 10.1037/0097-7403.20.4.366

Cerutti, D. A., (1989). Discrimination theory of rulegoverned behavior. Journal of Experimental Analysis of Behavior, 51, 259-276.

Craske, M. G., Hermans, D., \& Vervliet, B. (2018). Stateof-the-art and future directions for extinction as a translational model for fear and anxiety. Philosophical Transactions of the Royal Society B: Biological Sciences, 373, 20170025. http://dx.doi.org/10.1098/ rstb.2017.0025 
Craske, M. G., Kircanski, K., Zelikowsky, M., Mystkowsi, J., Chowdhury, N., \& Baker, A. (2008). Optimizing inhibitory learning during exposure therapy. Behaviour Research and Therapy, 46, 5-27. http:// dx.doi.org/10.1016/j.brat.2007.10.003

Craske, M. G., Treanor, M., Conway, C. C., Zbozinek, T., \& Vervliet, B. (2014). Maximizing exposure therapy: An inhibitory learning approach. Behaviour Research and Therapy, 58, 10-23. http://dx.doi.org/10.1016/ j.brat.2014.04.006

Culver, N. C., Stoyanova, M., \& Craske, M. G. (2011). Clinical relevance of retrieval cues for attenuating context renewal of fear. Journal of Anxiety Disorders, 25, 284-292. http://dx.doi.org/10.1016/ j.janxdis.2010.10.002

Dibbets, P., Havermans, R., \& Arntz, A. (2008). All we need is a cue to remember: the effect of an extinction cue on renewal. Behaviour Research and Therapy, 46, 1070-1077. http://dx.doi.org/10.1016/j.brat.20 08.05 .007

Laborda, M. A., Polack, C. W., Miguez, G., \& Miller, R. R. (2014). Behavioral techniques for attenuating the expression of fear associations in an animal model of anxiety. Journal of Behavior Therapy and Experimental Psychiatry, 45, 343-350. http://dx.doi. org/10.1016/j.jbtep.2014.02.005

Laborda, M. A., Schofield, C. A., Johnson, E. M., Schubert, J. R., George-Denn, D., Coles, M. E., \& Miller, R. R. (2016). The extinction and return of fear of public speaking. Behavior Modification, 40, 901-921. http:/ /dx.doi.org/10.1177/0145445516645766

McConnell, B.L., Miller, R.R. (2014). Associative accounts of recovery-from-extinction effects. Learning and Motivation, 46, 1-15. http://dx.doi.org/ 10.1016/j.lmot.2014.01.003

Mystkowski, J. L., Craske, M. G., Echiverri, A. M., \& Labus, J. S. (2006). Mental reinstatement of context and return of fear in spider-fearful participants. Behavior Therapy, 37, 49-60. http://dx.doi.org/ 10.1016/j.beth.2005.04.001

Nelson, J. B., Sanjuan, M. C., Vadillo-Ruiz, S., Pérez, J., \& León, S. P. (2011). Experimental renewal in human participants. Journal of Experimental Psychology:
Animal Behavior Processes, 37, 58-70. http:// dx.doi.org/10.1037/a0020519

Nieto, J., Uengoer, M., \& Bernal-Gamboa, R. (2017). A reminder of extinction reduces relapse in an animal model of voluntary behavior. Learning \& Memory, 24, 76-80. http://dx.doi.org/10.1101/lm.044495.116

Ogállar P. M., Ramos-Álvarez M. M., Alcalá J. A., Moreno-Fernández M. M., \& Rosas J. M. (2017). Attentional perspectives on context-dependence of information retrieval. International Journal of Psychology \& Psychological Therapy, 17, 115-130. Retrieved from https://www.ijpsy.com/volumen17/ num1/462.html

Pavlov, I. P. (1927).Conditioned reflexes. London: Oxford University Press.

Pritchard, D., Hoerger, M., \& Mace, F. C. (2014). Treatment relapse and behavioral momentum theory. Journal of Applied Behavior Analysis, 47, 814-833. http://dx.doi.org/10.1002/jaba.163

Podlesnik, C. A., \& Kelley, M. E. (2015). Translational research on the relapse of operant behavior. Mexican Journal of Behavior Analysis, 41, 226-251

Podlesnik, C. A., Kelley, M. E., Jimenez-Gomez, C., \& Bouton, M. E. (2017). Renewed behavior produced by context change and its implications for treatment maintenance: a review. Journal of Applied Behavior Analysis, 50, 675-697. http://dx.doi.org/10.1002/ jaba. 400

Romero, M. A., Vila, J., \& Rosas, J. M. (2005). Instructions inadequate to the task control response recovery after discrimination reversal in human beings. The Behavior Analyst Today, 6, 221-228.

Rosas, J. M., \& Callejas-Aguilera, J. E. (2006). Context switch effects on acquisition and extinction in human predictive learning. Journal of Experimental Psychology: Learning Memory and Cognition, 32, 461-474. http://dx.doi.org/10.1037/0278-7393.32. 3.461

Rosas, J. M., Callejas-Aguilera, J. E, Ramos-Álvarez, M. M., \& Abad, M. J. (2006). Revision of Retrieval Theory of Forgetting: What does make information context-specific? International Journal of Psychology and Psychological Therapy, 6, 147-166. 
Rosas, J. M., Todd, T. P., \& Bouton, M. E. (2013). Context change and associative learning. Wiley Interdisciplinary Reviews: Cognitive Science, 4, 237-244. http://dx.doi.org/10.1002/wcs.1225

Vansteenwegen, D., Vervliet, B., Hermans, D., Beckers, T., Baeyens, F., \& Eelen, P. (2006). Stronger renewal in human fear conditioning when tested with an acquisition retrieval cue than with an extinction retrieval cue. Behaviour Research and Therapy, 44, 1717-1725. http://dx.doi.org/10.1016/j.brat.2005. 10.014
Vervliet, B., Craske, M. G., \& Hermans, D. (2013). Fear extinction and relapse: State of the art. Annual Review of Clinical Psychology, 9, 215-248. http:// dx.doi.org/10.1146/annurev-clinpsy-050212-185542

Vila, N. J., \& Rosas, J. M. (2001). Renewal and spontaneous recovery after extinction in a causal learning task. Mexican Journal of Behavior Analysis, 27, 79-96.

Willcocks, A. L., \& McNally, G. P. (2014). An extinction retrieval cue attenuates renewal but not reacquisition of alcohol seeking. Behavioral Neuroscience, 128, 83-91, http://dx.doi.org/10.1037/a0035595

\section{Angélica Serena Alvarado García \\ Instituto Politécnico Nacional CICS-UST}

PhD in Experimental Psychology. Author of 15 international papers on associative learning. She has 4 chapters in specialized books. Her line of research focuses on associative learning in humans and memory retrieval processes.

ORCID: 0000-0001-6163-446X

aserena77@hotmail.com

Rodolfo Bernal-Gamboa

Universidad Nacional Autónoma de México

PhD in Experimental Analysis of Behavior. Author of 26 papers published in international journals. He has 8 chapters in specialized books. He has two lines of research: one focuses on learning and memory processes, and the other one on empathy and prosocial behaviors.

ORCID: 0000-0002-4096-8425

Corresponding author: rodolfo.bernalg@gmail.com

Javier Vila Carranza

Universidad Nacional Autónoma de México, FES Iztacala

PhD in Experimental Psychology. Author of 2 books. He has 69 papers on associative learning and behavioral pharmacology. His line of research focuses on associative learning in humans and memory retrieval processes.

ORCID: 0000-0002-1873-8949

javila@campus.iztacala.unam.mx 